\title{
Erosion of Grooved Surfaces by Cavitating Jet with Hydraulic Oil
}

\author{
Toshiharu Kazama, Kento Kumagai, Yasuhiro Osafune, Yukihito Narita, Shohei Ryu \\ College of Design and Manufacturing Technology, Muroran Institute of Technology, Muroran, Japan \\ Email: kazama@mmm.muroran-it.ac.jp
}

Received 11 December 2014; accepted 29 January 2015; published 27 March 2015

Copyright (C) 2015 by authors and Scientific Research Publishing Inc.

This work is licensed under the Creative Commons Attribution International License (CC BY). http://creativecommons.org/licenses/by/4.0/

cC) (i) Open Access

\section{Abstract}

To study the effect of impingement surface geometry, a cavitation erosion experiment was conducted using a submerged cavitating jet rig with hydraulic oil. The test setup comprised a test chamber with a long-orifice nozzle, a hydraulic pump with an electric motor, hydraulic auxiliaries, including valves, a cooler, a filter, a reservoir, and measuring instruments, including pressure gages and a thermometer. Hexahedral specimens made of aluminum alloy with flat and grooved surfaces and oblique angles were prepared. Hydraulic oil with a viscosity grade of 32 was used at $40^{\circ} \mathrm{C}$ as the test fluid. The upstream absolute pressure was kept at $10.1 \mathrm{MPa}$ and the cavitation numbers were set at $0.02-0.04$. The results of this experiment yielded the following conclusions. The mass loss of the grooved specimens did not increase monotonically as the exposure time increased. The standoff distances at the maximum mass loss for the flat and grooved specimens were almost equivalent. The mass loss decreased as the oblique angle increased and the cavitation number increased, regardless of the presence of grooves. The surfaces were eroded in a ring-like region, but the region elongated as the angle increased. For the grooved specimens, the ridges on the ring were eroded, and when the directions of the grooves and the flow matched, the roots and flanks were severely eroded.

\section{Keywords}

Oil-Hydraulics, Cavitation, Erosion, Jet, Grooves

\section{Introduction}

Cavitation and cavitation erosion [1] [2] diminish the reliability and durability as well as the feasible operation and performance of hydraulic components and fluid power systems. The impingement of a cavitating jet of highly pressurized liquid is the main cause of erosion in hydraulic valves, pumps, and motors. This erosion is the 
result of the collapse of bubbles at or near the solid boundaries. The reduction of erosion caused by cavitating jets would improve the efficiency of hydraulic equipment and extend the lifespan of hydraulic systems.

The phenomena of cavitation [3] [4] and the mechanisms of cavitation erosion [5] are extremely complicated, and thus are not yet entirely understood, despite the substantial research that has been performed on this topic. To perform a material assessment, the erosion is often evaluated using the vibratory [6] and jet methods [7]. The former method has been used more frequently, but the results obtained using the latter method are more relevant to oil-hydraulic equipment because of the similarity of the flow fields.

Lichtarowicz [8] proposed a submerged cavitating jet apparatus about 40 years ago. Using prototypes based on Lichtarowicz's apparatus, Kleinbreuer [9], Yamaguchi and Shimizu [10], Momma and Lichtarowicz [11], Soyama et al. [12] [13], Steller [14], Mann and Arya [15], Hattori et al. [16] [17], and others have extensively studied erosion due to cavitating jets. However, all experimental studies to date have been done using water, with a few exceptions [9] [10]. The aspect and degree of erosion are different with water and oil, although in general, erosion with water is harder than that with oil. Thus, there is less information about cavitation erosion in oil hydraulic systems. The experimental results, particularly focusing on reducing erosion with oil, would be useful and helpful for design of hydraulic components.

This study investigates cavitation erosion behavior using a jet cavitation rig based on its application to hydraulic equipment in a manner similar to [10]. The primary focus of this study is the effect of fluids and flow on erosion. The experimental parameters include upstream pressure and cavitation number [18], nozzle outlet geometry [19], specimen configuration [20], pressure pulsation [21], nozzle size [22], fluid types, including tap water and several oils [18], material properties [23], and differences in test methods [23].

In actual equipment, such as valves, cavitation erosion often occurs at the thread and on the curved, inclined wall. There are few studies on the cavitation of oblique impingement on solid surfaces [24], and there have been no attempts to study the cavitation erosion of grooved surfaces with oils [25]. Therefore, in this study, we examined cavitation erosion resulting from the impingement of hydraulic oil on both grooved and oblique surfaces. The time-series mass loss was obtained by weighing the specimens at regular time intervals; the surfaces after the test were examined using a digital camera and a scanning electron microscope (SEM). In addition, this study discusses the effects of the standoff distance and the cavitation number.

\section{Experimental Apparatus and Conditions}

\subsection{Test Apparatus}

The apparatus and procedures used for this study [25] [26] were similar to those prescribed in the American Society for Testing and Materials (ASTM) standards [7], but with slightly different test conditions and geometry [10]. The apparatus, specimens, conditions, and procedures of the experimental study are described below.

The hydraulic circuit for testing erosion with hydraulic oil comprised a test chamber; a positive displacement pump with an electric motor; accessories, including valves, a cooler, a filter, and a reservoir; and instruments, including pressure gages and a thermometer. The pump was a vane-type hydraulic pump with a maximum operating pressure and discharge of $40 \mathrm{MPa}$ and $2.3 \times 10^{-4} \mathrm{~m}^{3} / \mathrm{s}$, respectively. The inline filter had a nominal pore size of $3 \mu \mathrm{m}$ to remove contaminants from the test liquid. The cooler maintained the temperature of the liquid at the required value.

The arrangement of the test chamber is presented in Figure 1. The stainless steel chamber, with an inner diameter of $170 \mathrm{~mm}$, included a long-orifice nozzle (1 mm in diameter and $4 \mathrm{~mm}$ in length), its holder, the specimen, its mount, and spacers. The bulk velocity of the jet could approximately be estimated at $100-150 \mathrm{~m} / \mathrm{s}$ because the flow in the nozzle was chocked. Using the annular spacers, the standoff distance $L$ was increased from 15 to $30 \mathrm{~mm}$ in increments of $2.5 \mathrm{~mm}$. $L$ is defined as the distance from the edge-face of the nozzle outlet to the thread root of the specimen surface on the center axis, as indicated in Figure 2(a). Two transparent windows were installed on both sides of the chamber to allow the observation of the cavitating jet. The chamber was installed in a double soundproof box because of the loud high-frequency noise it generated.

\subsection{Test Specimens}

The essential part of the specimens were hexahedral or cuboid, with $15 \mathrm{~mm} \times 15 \mathrm{~mm}$ square surfaces (the grooved specimen with the angle $\alpha$ of $60^{\circ}$ is shown in Figure 2(b)), fabricating a flange to attach the mount. The 


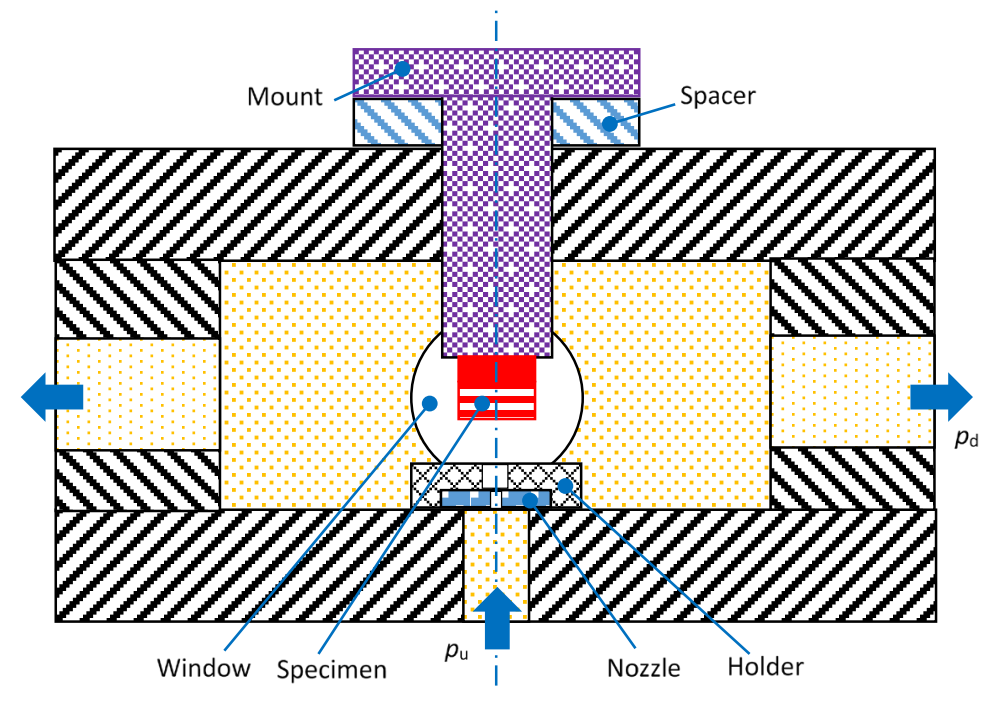

Figure 1. Test chamber of the cavitating jet test rig.

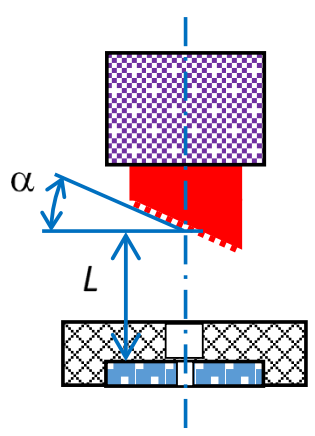

(a)

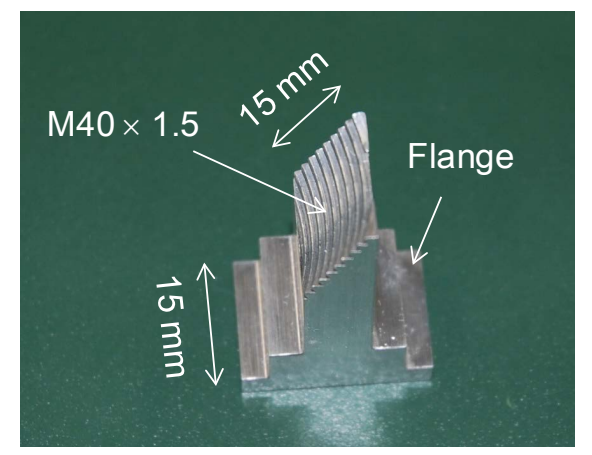

(b)

Figure 2. (a) Specimen angle $\alpha$ and standoff distance $L$; (b) Geometry of grooved specimen $\left(\alpha=60^{\circ}\right)$.

impinging surfaces were oblique, with angles $\alpha$ of $0^{\circ}, 15^{\circ}, 30^{\circ}, 45^{\circ}$, and $60^{\circ}$ with respect to the horizontal; $\alpha=0^{\circ}$ corresponded to the jet impinging perpendicular to the specimen surface. For each angle, two types of specimens were provided: one with a flat surface and one with a grooved surface threaded with metric fine pitch M40 thread, yielding a total of ten different specimens. Following the Japanese Industrial Standards (JIS), the pitch was $1.5 \mathrm{~mm}$, the thread overlap was $0.812 \mathrm{~mm}$, and the radius of curvature of the roots was $20 \mathrm{~mm}$. The material of the specimens was A5056 aluminum alloy (JIS H4040), as designated by JIS and corresponding to AlMg5 in Deutsches Institutfür Normung (DIN).

\subsection{Test Conditions}

The liquid tested in this study was a mineral-oil-based hydraulic fluid with an ISO viscosity grade of 32 and kinematic viscosities of 32.6 and $5.49 \mathrm{~mm}^{2} / \mathrm{s}$ at $40^{\circ} \mathrm{C}$ and $100^{\circ} \mathrm{C}$, respectively. By using the inline cooler and recirculating the test liquid in the hydraulic circuit, the temperature $T$ was set to $40^{\circ} \mathrm{C} \pm 1^{\circ} \mathrm{C}$. The upstream absolute pressure $p_{\mathrm{u}}$ was maintained at $10.1 \mathrm{MPa}$, and the downstream absolute pressure $p_{\mathrm{d}}$ was set at $0.2,0.3$, and 0.4 MPa. These conditions yielded that the cavitation number $\sigma$, defined as the ratio of the downstream pressure $p_{\mathrm{d}}$ to the upstream pressure $p_{\mathrm{u}}$, i.e., $\sigma=p_{\mathrm{d}} / p_{\mathrm{u}}$, was kept between 0.02 and 0.04 .

\subsection{Test Procedure}

At the beginning of each test, the standoff distance $L$ was set using the spacers. The chamber was filled with the 
test oil. The remaining air and bubbles were then removed carefully from the chamber. The oil temperature $T$ was elevated to $40^{\circ} \mathrm{C}$ by a warming-up operation. Pressurized oil was supplied from a constant pressure source at pressure $p_{\mathrm{u}}$. The submerged jet was cavitated through the nozzle and discharged into the chamber at a constant pressure $p_{\mathrm{d}}$. The cavitating jet was impinged upon the specimen surface. The pressures $p_{\mathrm{u}}$ and $p_{\mathrm{d}}$ and the temperature $T$ were monitored continuously and controlled manually to maintain the prescribed experimental conditions during each test.

Pump operation was interrupted at regular intervals of 15 min during the first hour of the exposure period ( 0 $1 \mathrm{~h}$ ), at intervals of $30 \mathrm{~min}$ between the first and second hour of the exposure period ( $1-2 \mathrm{~h}$ ), and at intervals of $1 \mathrm{~h}$ for the exposure period after $2 \mathrm{~h}$. The interruption for instrumentation was repeated during a specific period of up to $8 \mathrm{~h}$. At each interval, the specimen was removed carefully and rinsed thoroughly with heptane. The mass was determined using a precision balance with an accuracy and sensitivity of $0.1 \mathrm{mg}$. Each eroded specimen's surface was photographed and observed. The sectional profile of the flat specimen's surface was recorded using a contact-type profilometer. After the erosion test, some specimens were examined by SEM.

\section{Results and Discussion}

Figure 3(a) and Figure 3(b) show the time evolution of the mass loss $M$ and the cumulative erosion rate ERof the flat specimens, respectively, for the standoff distance range $L=20$ to $30 \mathrm{~mm}$ with $2.5 \mathrm{~mm}$ increments, where the jet impinged perpendicular to the specimen surface $\left(\alpha=0^{\circ}\right)$ at a cavitation number of $\sigma=0.02$. Figure 4(a) and Figure 4(b) show the time evolution of $M$ and $E R$ of the grooved specimens, respectively. $M$ of the flat specimens increased smoothly with time, whereas $M$ of the grooved specimens increased at inconsistent rates. $M$ and $E R$ in both cases remained near zero for approximately one to two hours, which is well known to be the incubation period [2], and then increased at an accelerated rate or linearly for all values of $L$.

Figure 5 and Figure 6 illustrate the mass loss $M$ with respect to the standoff distance $L$ for the oblique flat and grooved specimens at angles $\alpha=0^{\circ}, 15^{\circ}, 30^{\circ}, 45^{\circ}$, and $60^{\circ}$. The lines connect the individual data sets at each stage, whereas for both the specimens at $\alpha=0^{\circ}$, the lines connect the average values of the data. The maximum mass loss $M$ occurred at $L=25$ and $27.5 \mathrm{~mm}$ for the flat specimens and at $L=27.5 \mathrm{~mm}$ for the grooved specimens; these values of $L$ were designated as $L_{\max }$. Although there was some variation in the data, the distances $L_{\max }$ that resulted in the maximum mass loss were nearly equivalent. The loss $M$ at $L_{\max }$, designated as $M_{\max }$, was largest in the case of the specimen with $\alpha=0^{\circ}$, followed by $M_{\max }$ at angles $\alpha=15^{\circ}, 30^{\circ}, 45^{\circ}$, and $60^{\circ}$ for both flat and grooved specimens. In general, as $\alpha$ increased, $M$ decreased, but this trend was weak for the grooved specimens.

Figure 7 and Figure 8 show the results of the effects of the cavitation number $\sigma$ and the impingement angle $\alpha$ on the mass loss $M$ at a distance of $L_{\max }$ for the flat and grooved specimens, respectively. For both specimen

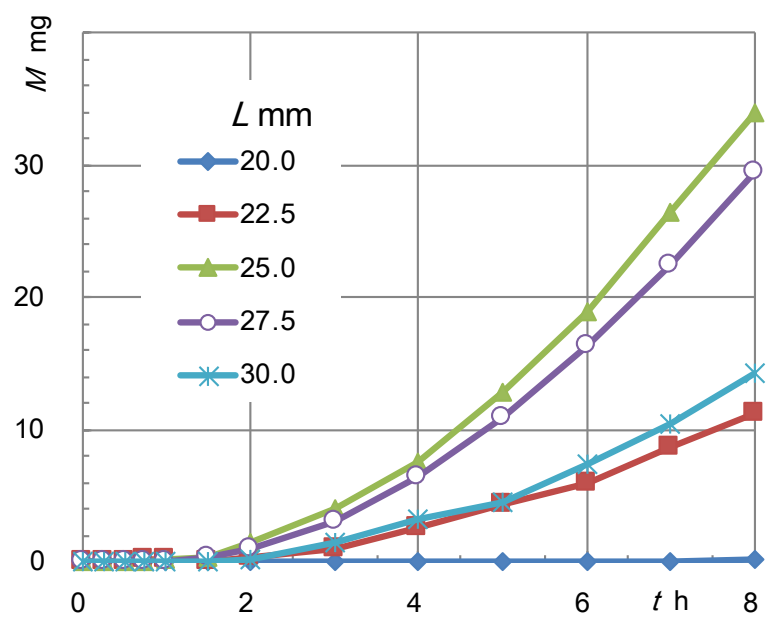

(a)

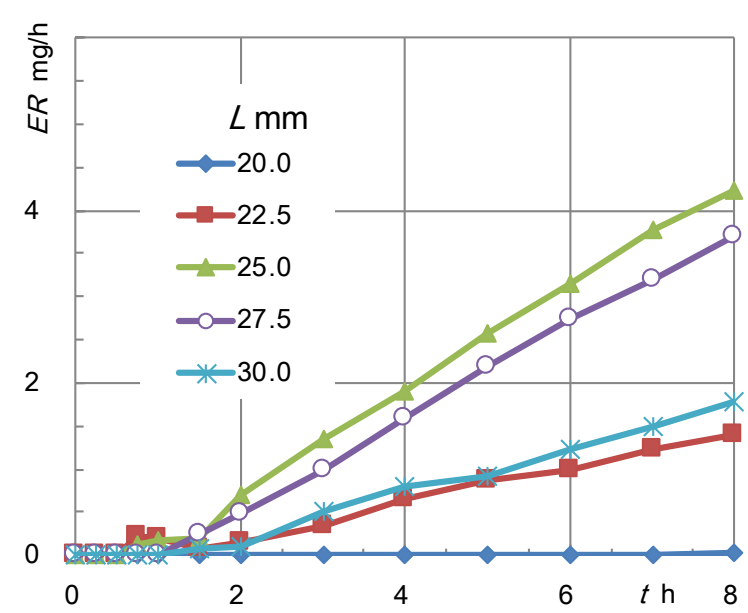

(b)

Figure 3. (a) Time evolution of mass loss $M$ in terms of standoff distance $L$ (Flat, $\alpha=0^{\circ}, \sigma=0.02$ ); (b) Erosion rate $E R$ in terms of standoff distance $L$ (Flat, $\alpha=0^{\circ}, \sigma=0.02$ ). 


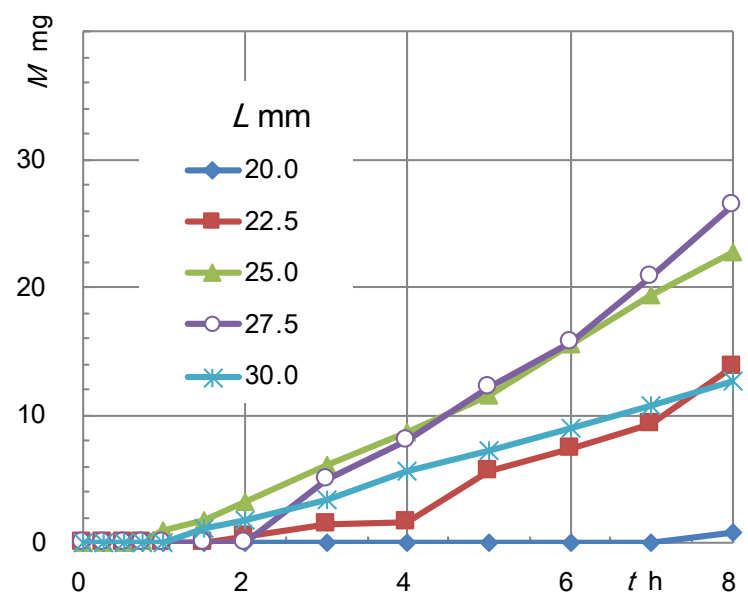

(a)

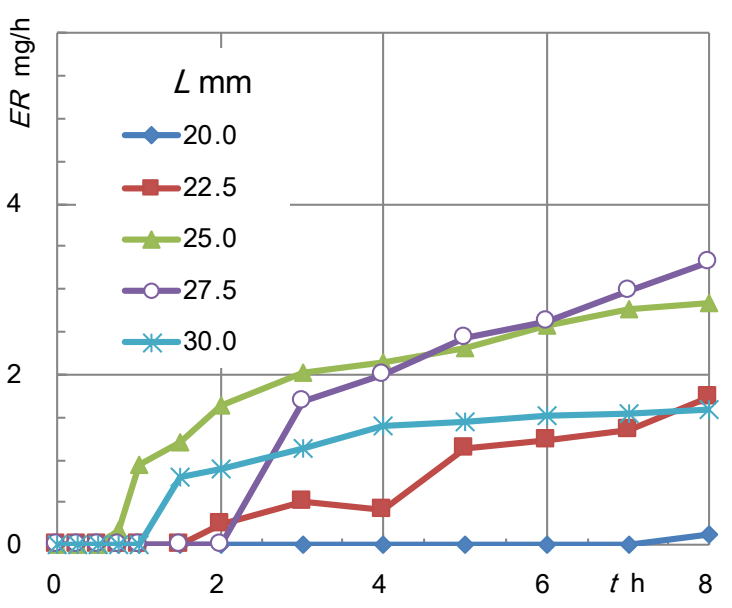

(b)

Figure 4. (a) Time evolution of mass loss $M$ in terms of standoff distance $L$ (Grooved, $\alpha=0^{\circ}, \sigma=0.02$ ); (b) Erosion rate $E R$ in terms of standoff distance $L$ (Grooved, $\alpha=0^{\circ}, \sigma=0.02$ ).

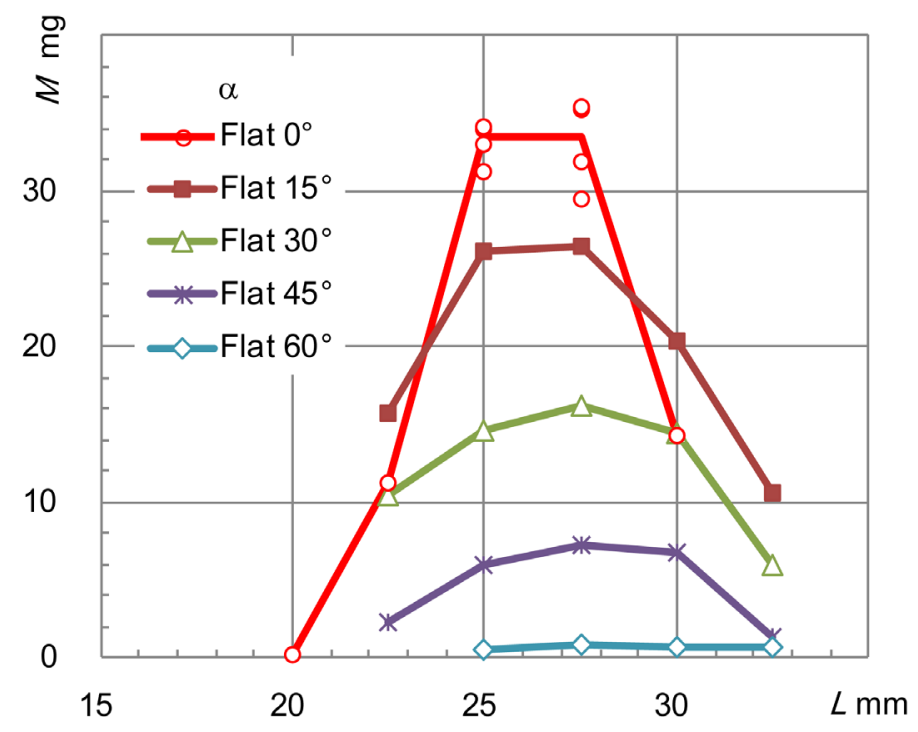

Figure 5. Effects of impingement angle $\alpha$ on mass loss $M$ for standoff distance $L$ (Flat, $t=8 \mathrm{~h}, \sigma=0.02$ ).

types, $M$ increased as the number $\sigma$ and angle $\alpha$ decreased. For the specimens with smaller $\sigma$ values, the mass loss $M$ of the flat specimen was larger than that of the grooved specimen. In contrast, for the specimens with larger $\sigma$ values, $M$ of the grooved specimen was larger. In particular, $M$ of the flat specimen with $\alpha=60^{\circ}$ was nearly independent of $\sigma$. That is, $\sigma$ and $\alpha$ affected the flat specimens more than the grooved specimens, particularly under larger $M$ conditions.

Figure 9 and Figure 10 show the time series of the photographs of the eroded specimens with flat and grooved surfaces, respectively. As the exposure time $t$ increased, the surfaces were eroded in a ring-like pattern [7]. An eroded ring and axisymmetric damage for the flat specimen are clearly visible in Figure 9 from very early stages. In contrast, for the grooved specimen in Figure 10, the ring-shaped eroded regions were initially only minimally visible and became more visible as time $t$ increased.

Figure 11 shows the SEM micrographs of the eroded specimen surfaces. Figure 11(a) is an image of the edge of the specimen surface, and Figure 11(b) is of a region much further from the edge. The root and flank were eroded in Figure 11(a), but the ridges were eroded in Figure 11(b). 


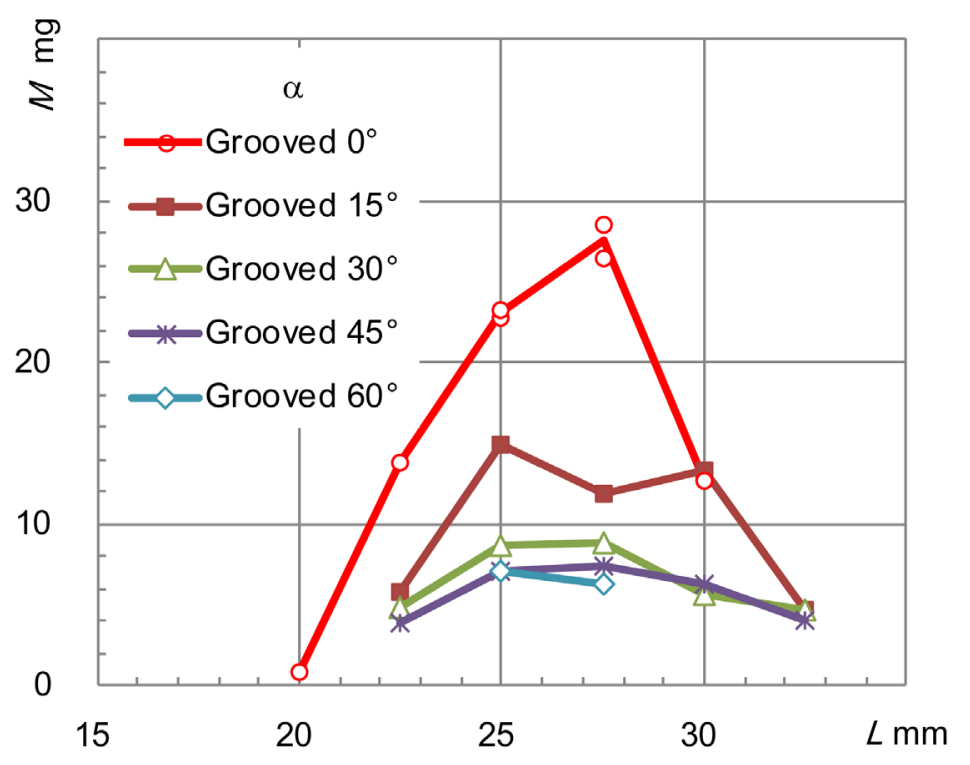

Figure 6. Effects of impingement angle $\alpha$ on mass loss $M$ for standoff distance $L$ (Grooved, $t=8 \mathrm{~h}, \sigma=0.02$ ).

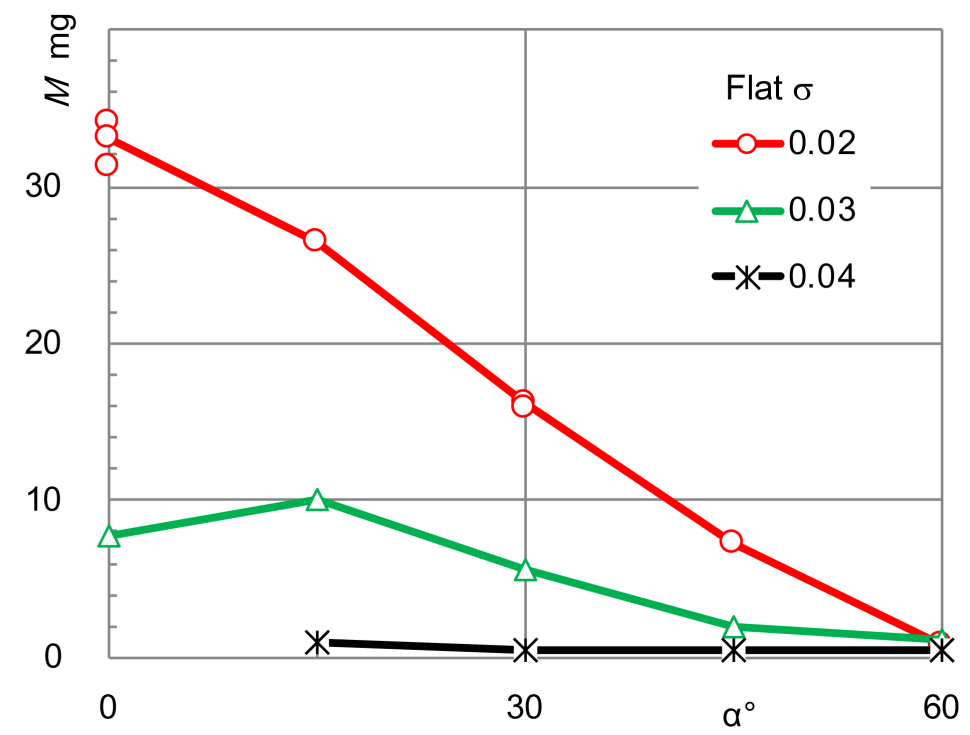

Figure 7. Effects of cavitation number $\sigma$ and specimen angle $\alpha$ on mass loss $M$ (Flat, $L=L_{\max }, t=8 \mathrm{~h}$ ).

From these images, it should be noted that in the ring-shaped eroded region of the grooved surface, the ridges were eroded; however, close to the edges of the specimens (top and bottom of each image in Figure 10), the roots and flanks were severely damaged. This may be caused by the similar direction of the flow and the grooves; the impinging jet could flow more easily along the grooves, and bubbles were more likely to collapse near the surface close to the roots.

Figure 12 and Figure 13 are photographs of the eroded specimen surfaces of the flat and grooved specimens, respectively, categorized by cavitation number $\sigma$ and oblique angle $\alpha$. The picture at the condition of $\sigma=0.04$ and $\alpha=0^{\circ}$ in Figure 12 is absent because the experiment of the condition was not performed. Figure 12 demonstrates that the erosion was more exaggerated for lower $\sigma$ and the eroded regions of the specimen surfaces with $\alpha$ $=0^{\circ}$ were ring shaped, while the ring shape elongated as $\alpha$ increased, which also happened for the grooved spe- 


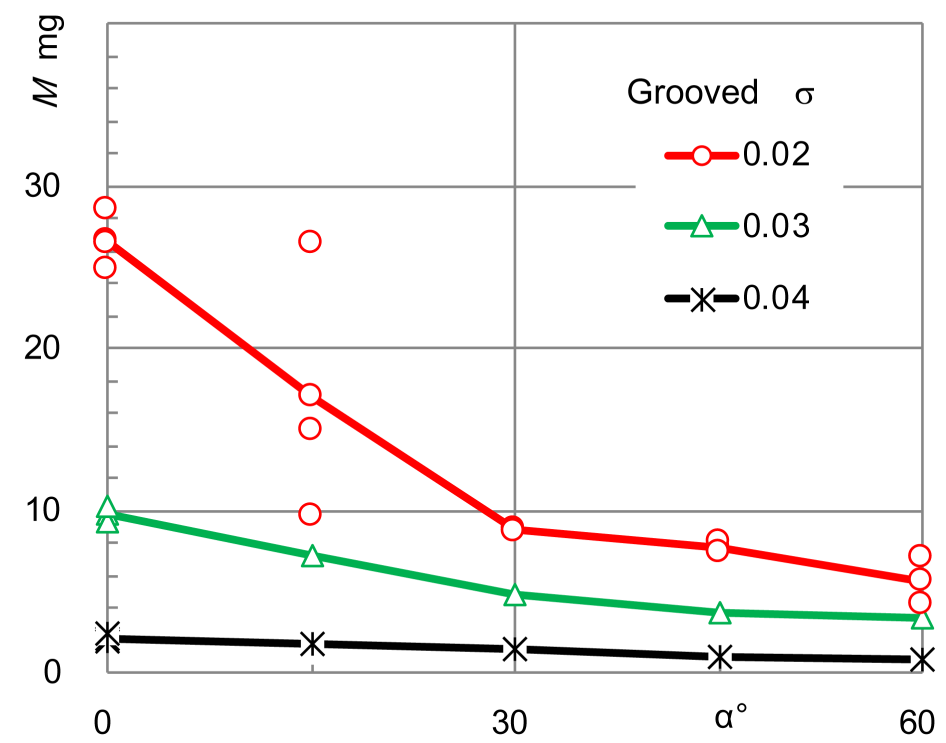

Figure 8. Effects of cavitation number $\sigma$ and specimen angle $\alpha$ on mass loss $M$ (Grooved, $L=L_{\max }, t=8 \mathrm{~h}$ ).

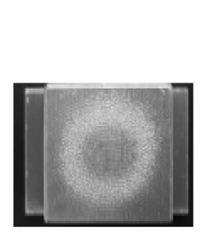

$t=15 \mathrm{~min}$

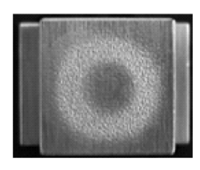

$1 \mathrm{~h}$

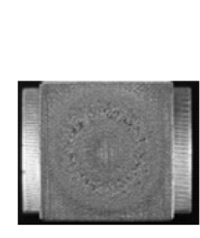

$4 \mathrm{~h}$

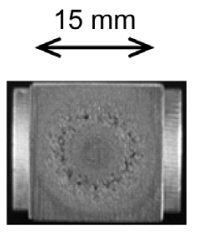

$8 \mathrm{~h}$

Figure 9. Time series photographs of eroded surfaces of flat specimen $(L=$ $\left.27.5 \mathrm{~mm}, \alpha=0^{\circ}, \sigma=0.02\right)$.

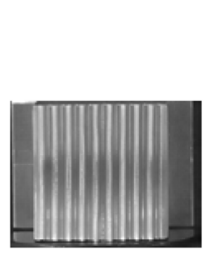

$t=15 \min$

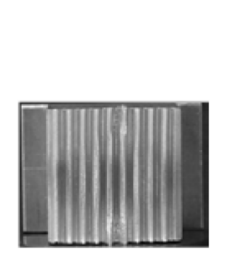

$1 \mathrm{~h}$

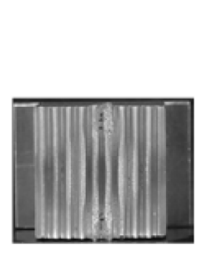

$4 \mathrm{~h}$

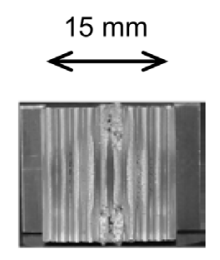

$8 \mathrm{~h}$

Figure 10. Time series photographs of eroded surfaces of grooved specimen $\left(L=27.5 \mathrm{~mm}, \alpha=0^{\circ}, \sigma=0.02\right)$.
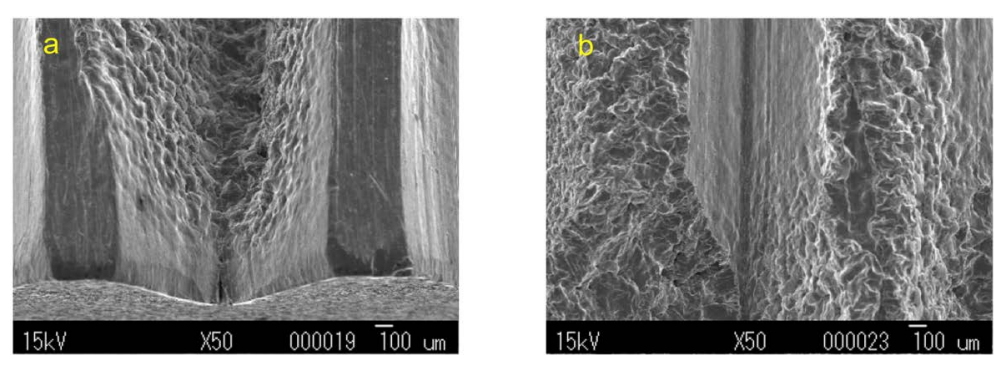

Figure 11. (a) SEM micrographs of eroded surface at edge (Grooved, $\alpha=0^{\circ}$, $\sigma=0.02$ ); (b) Inner eroded surface (Grooved, $\alpha=0^{\circ}, \sigma=0.02$ ). 


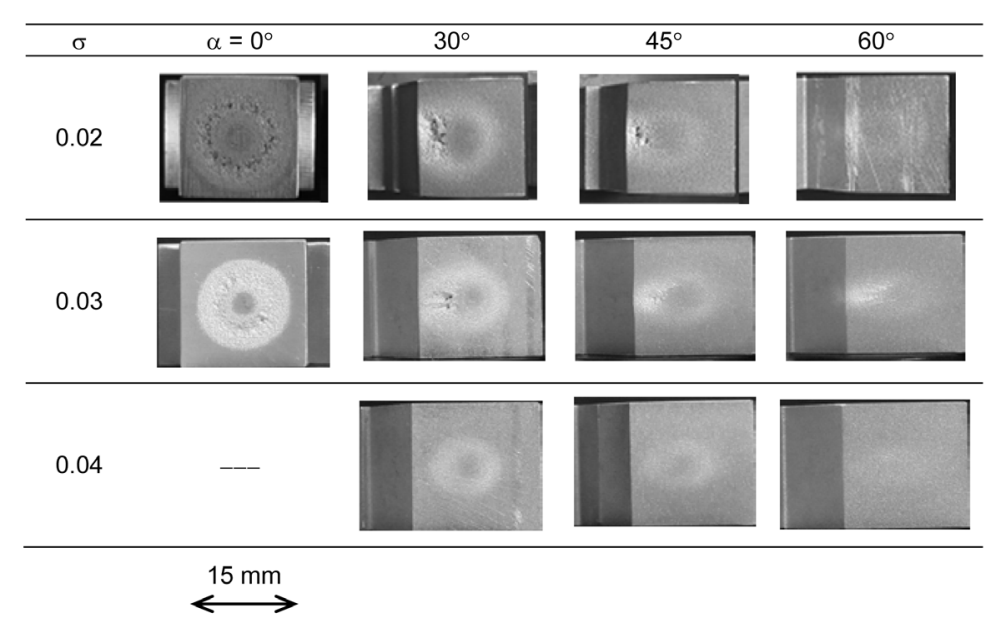

Figure 12. Photographs of eroded surfaces of flat specimen with different angles $\left(L=L_{\max }, t=8 \mathrm{~h}\right)$.

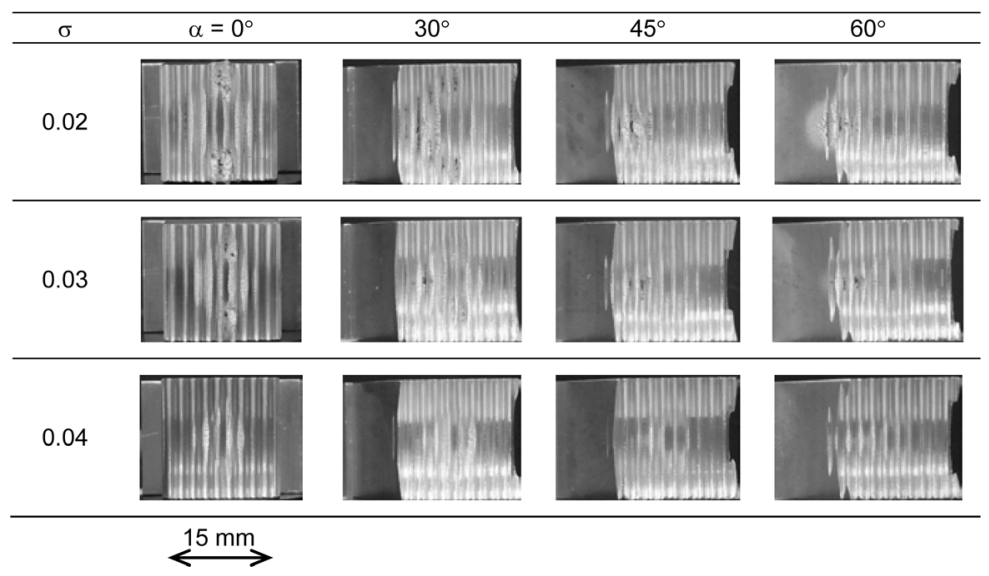

Figure 13. Photographs of eroded surfaces of grooved specimen with different angles $\left(L=L_{\max }, t=8 \mathrm{~h}\right)$.

cimens shown in Figure 13. The erosion of the flat surface under the conditions of $\sigma=0.04$ and $\alpha=60^{\circ}$ was negligible compared to that under other conditions. In addition, the surfaces simultaneously eroded in a confined region on the left-hand side of each photo, corresponding to the downstream side of the cavitating jet.

As with the flat specimens shown in Figure 12, the grooved surfaces in Figure 13 were locally damaged close to the top and bottom edges with $\alpha=0^{\circ}$, and ring-like regions of erosion were visible. The effect of the number $\sigma$ and the angle $\alpha$ on the extent of the erosion of the grooved specimens was very similar to that of the flat specimens, but the effect on the grooved specimens was weaker, which corresponded to the mass loss in Figure 7 and Figure 8.

\section{Conclusions}

Experiments measuring erosion caused by the impingement of submerged cavitating jets were performed for application to hydraulic equipment. The effects of the geometry of the jet-impinged surfaces were demonstrated in terms of the eroded mass loss and surface features. Influences of thread grooves using the thread of metric fine pitch M40, impingement angles up to $60^{\circ}$, standoff distances within $20-35 \mathrm{~mm}$, and cavitation numbers of 0.02 - 0.04 were also examined systematically. The most noteworthy conclusions are described as follows:

i) Compared to the flat specimens, the mass loss of the grooved specimens did not increase monotonically as the exposure time increased. The influence of the oblique angles and the cavitation number on the mass loss of the grooved specimens was smaller than that of the flat specimens. 
ii) The standoff distances where the mass loss was maximized for the flat and grooved specimens were almost equivalent. The mass loss was maximized when the jet impinged perpendicularly onto the specimen surfaces. Under the present test conditions, the mass loss decreased as the angle increased and the cavitation number increased, regardless of the presence of surface grooves.

iii) The surfaces were eroded in a ring-like region when the jet impinged perpendicularly onto the specimen, and the region elongated as the angle increased. Additionally, specimens located further from the nozzle were eroded more. For the grooved specimens, the ridges on the erosion ring were eroded, and the roots and flanks on the ring were severely eroded in regions where the directions of the grooves and the flow were the same.

\section{Acknowledgements}

The authors would like to thank Mr. A. Nakayama of Hitachi Construction Machinery Co., Ltd. They also thank Y. Niida of Muroran Institute of Technology, and K. Akiyama, D. Sasaki, T. Tomida, and M. Sudo-former students of Muroran Institute of Technology—for their cooperation in performing this experiment.

\section{References}

[1] Plesset, M.S. and Devine, R.E. (1966) Effect of Exposure Time on Cavitation Damage. Journal of Basic Engineering, Transactions of ASME, 88, 691-705. http://dx.doi.org/10.1115/1.3645943

[2] Knapp, R.T., Daily, J.W. and Hammitt, F.G. (1970) Cavitation. McGraw Hill, New York.

[3] Caupin, F. and Herbert, E. (2006) Cavitation in Water: A Review. Comptes Rendus Physique, 7, 1000-1017. http://dx.doi.org/10.1016/j.crhy.2006.10.015

[4] Peng, G. and Shimizu, S. (2013) Progress in Numerical Simulation of Cavitating Water Jets. Journal of Hydrodynamics, B, 25, 502-509. http://dx.doi.org/10.1016/S1001-6058(11)60389-3

[5] Van Terwisga, T.J.C., Fitzsimmons, P.A., Li, Z. and Foeth, E.J. (2009) Cavitation Erosion-A Review of Physical Mechanisms and Erosion Risk Models. Proceedings of the 7th International Symposium on Cavitation CAV2009, Ann Arbor, 17-22 August 2009, 14.

[6] ASTM (1989) Standard Method of Vibratory Cavitation Erosion Test. Annual Book ASTM Standards, G32.85, 142147.

[7] ASTM (1995) Standard Test Method for Erosion of Solid Materials by a Cavitating Liquid Jet. Annual Book of ASTM Standards, G134.95, 529-540.

[8] Lichtarowicz, A. (1972) Use of a Simple Cavitating Nozzle for Cavitation Erosion Testing and Cutting. Nature; Physical Science, 239, 63-64. http://dx.doi.org/10.1038/physci239063a0

[9] Kleinbreuer, W. (1977) Kavitationserosion in Hydraulischen Systemen. Industrie-Anzeiger, 99, 609-613.

[10] Yamaguchi, A. and Shimizu, S. (1987) Erosion Due to Impingement of Cavitating Jet. Journal of Fluids Engineering, Transactions of ASME, 109, 442-447. http://dx.doi.org/10.1115/1.3242686

[11] Momma, T. and Lichtarowicz, A. (1995) Study of Pressures and Erosion Produced by Collapsing Cavitation. Wear, 186-187, 425-436. http://dx.doi.org/10.1016/0043-1648(95)07144-X

[12] Soyama, H., Lichtarowicz, A., Momma, T. and Williams, E.J. (1998) A New Calibration Method for Dynamically Loaded Transducers and Its Application to Cavitation Impact Measurement. Journal of Fluids Engineering, Transactions of ASME, 120, 712-718.

[13] Soyama, H. (2013) Effect of Nozzle Geometry on a Standard Cavitation Erosion Test Using a Cavitating Jet. Wear, 297, 895-902. http://dx.doi.org/10.1016/j.wear.2012.11.008

[14] Steller, J. (1999) International Cavitation Erosion Test and Quantitative Assessment of Material Resistance to Cavitation. Wear, 233-235, 51-64. http://dx.doi.org/10.1016/S0043-1648(99)00195-7

[15] Mann, B.S. and Arya, V. (2002) An Experimental Study to Correlate Water-Jet Impingement Erosion Resistance and Properties of Metallic Materials and Coatings. Wear, 253, 650-661. http://dx.doi.org/10.1016/S0043-1648(02)00118-7

[16] Hattori, S., Goto, Y. and Fukuyama, T. (2006) Influence of Temperature on Erosion by a Cavitating Liquid Jet. Wear, 260, 1217-1223. http://dx.doi.org/10.1016/j.wear.2005.08.001

[17] Hattori, S., Hirose, T. and Sugiyama, K. (2010) Prediction Method for Cavitation Erosion Based on Measurement of Bubble Collapse Impact Loads. Wear, 269, 507-514. http://dx.doi.org/10.1016/j.wear.2010.05.015

[18] Kazama, T. and Shimizu, K. (2007) Erosion Due to Impingement of Submerged Cavitating Jets in Tap Water, Biodegradable and Mineral Oils. Proceedings of the Tenth Scandinavian International Conference on Fluid Power, SICFP'07, Tampere, 21-23 May 2007, 91-105. 
[19] Kazama, T. and Miura, Y. (2007) Reduction in Submerged Jet Cavitation Erosion (Flow Control by Geometry Close to Nozzle Outlets and Impinged Surfaces). Transactions of Japan Fluid Power System Society, 38, 77-82. http://dx.doi.org/10.5739/jfps.38.77

[20] Shimizu, S., Yamaguchi, A. and Kazama, T. (1991) Erosion Due to Impingement of a Cavitating Jet (2nd Report: Effects of Nozzle Holder and Configuration of Impingement Surface). Journal of Japan Hydraulics and Pneumatics Society, 22, 57-62. http://dx.doi.org/10.5739/jfps1970.22.57

[21] Yamaguchi, A., Wang, X. and Kazama, T. (1997) Erosion Due to Impingement of a Cavitating Jet (4th Report: Effects of Nozzles Shape and Upstream Pressure Pulsation). Journal of Japan Hydraulics and Pneumatics Society, 28, 353358. http://dx.doi.org/10.5739/jfps1970.28.353

[22] Kazama, T. and Yamaguchi, A. (2000) Effects of Configuration of Nozzles, Outlets of Nozzles and Specimens on Erosion Due to Impingement of Cavitating Jet. Proceedings of the 48th National Conference on Fluid Power, Chicago, 4-6 April 2000, 263-272.

[23] Yamaguchi, A., Kazama, T., Inoue, K. and Onoue, J. (2001) Comparison of Cavitation Erosion Test Results between Vibratory and Cavitating Jet Methods. International Journal of Fluid Power, 2, 25-30. http://dx.doi.org/10.1080/14399776.2001.10781099

[24] Kazama, T., Kumagai, K., Osafune, Y., Narita, Y. and Ryu, S. (2013) Effects of Oblique Surfaces with Grooves on Erosion by Cavitating Oil Jet. Proceedings of the 12th International Symposium on Fluid Control, Measurement and Visualization (FLUCOME 2013), Nara, 18-22 November 2013, OS1-03-4, 1-10.

[25] Sugimoto, Y., Jibiki, Y. and Sato, K. (2010) Behavior and Erosion of Cavitating Jet Impinging on Oblique Surface. Japanese Journal of Multiphase Flow, 24, 697-702. http://dx.doi.org/10.3811/jjmf.24.697

[26] Kazama, T., Kumagai, K., Miura, Y. and Narita, Y. (2009) Reduction and Enlargement of Erosion by a Submerged Cavitating Jet with Geometric Control. Proceedings of the 9th Pacific Rim International Conference on Water Jetting Technology, Koriyama, 20-23 November 2009, 123-131.

\section{Nomenclature}

$D$ : Erosion ring diameter [mm]

$E R$ : Mass loss rate $[\mathrm{mg} / \mathrm{h}]$

$L$ : Standoff distance [mm]

$p_{\mathrm{d}}$ : Downstream absolute pressure $[\mathrm{MPa}]$

$p_{\mathrm{u}}$ : Upstream absolute pressure [MPa]

$t$ : Exposure time [h]

$\alpha$ : Specimen angle $\left[{ }^{\circ}\right]$

$\sigma$ : Cavitation number $=p_{\mathrm{d}} / p_{\mathrm{u}}$ 